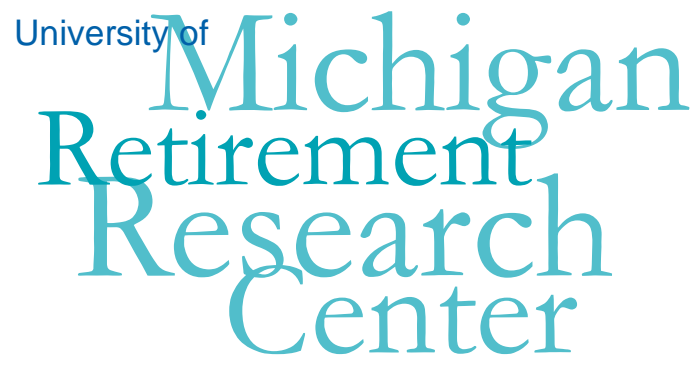

Working Paper

WP 2012-263

\title{
Behavioral Effects of Social Security Policies on Benefit Claiming, Retirement and Saving
}

\author{
Alan L. Gustman and Thomas L. Steinmeier
}

\begin{tabular}{|l|l|}
\hline $\mathrm{M}$ & $\mathrm{R}$ \\
\hline $\mathrm{R}$ & $\mathrm{C}$ \\
\hline
\end{tabular}

Project \#: UM12-04 



\title{
Behavioral Effects of Social Security Policies on Benefit Claiming, Retirement and Saving
}

\author{
Alan L. Gustman \\ Dartmouth College \\ Thomas L. Steinmeier \\ Texas Tech University \\ August 2012 \\ Michigan Retirement Research Center \\ University of Michigan \\ P.O. Box 1248 \\ Ann Arbor, MI 48104 \\ http://www.mrrc.isr.umich.edu \\ (734) 615-0422
}

\section{Acknowledgements}

This work was supported by a grant from the Social Security Administration through the Michigan Retirement Research Center (Grant \# 5 RRC08098401-04-00). The findings and conclusions expressed are solely those of the author and do not represent the views of the Social Security Administration, any agency of the Federal government, or the Michigan Retirement Research Center.

\section{Regents of the University of Michigan}

Julia Donovan Darrow, Ann Arbor; Laurence B. Deitch, Bloomfield Hills; Denise Ilitch, Bingham Farms; Olivia P. Maynard, Goodrich; Andrea Fischer Newman, Ann Arbor; Andrew C. Richner, Grosse Pointe Park; S. Martin Taylor, Gross Pointe Farms; Katherine E. White, Ann Arbor; Mary Sue Coleman, ex officio 


\title{
Behavioral Effects of Social Security Policies on Benefit Claiming, Retirement and Saving
}

\begin{abstract}
This paper specifies three behavioral variants of a structural model of retirement and saving to bring predicted Social Security claiming rates closer to the rates observed in the data. The model, estimated with Health and Retirement Study data, is used to examine three potential policies: increasing early entitlement age, increasing normal retirement age, and eliminating payroll taxes after normal retirement age. Behavioral responses to increasing early entitlement age and eliminating the payroll tax are not affected by the behavioral variant used. Predicted effects of increasing the normal retirement age exhibit more sensitivity. Heterogeneity shapes the responses to these policy changes.
\end{abstract}




\title{
Behavioral Effects of Social Security Policies on Benefit Claiming, Retirement and Saving
}

\author{
Alan L. Gustman \\ Dartmouth College \\ and \\ Thomas L. Steinmeier \\ Texas Tech University
}

UM12-04

August, 2012

\begin{abstract}
Alan L. Gustman. Department of Economics. Dartmouth College. Hanover, N.H. 03755.
Phone: (603)646-2641. Email: Alan.L.Gustman@ Dartmouth.edu

Thomas L. Steinmeier, Department of Economics, Texas Tech University, Lubbock, Texas 70409. Phone: 806-4017183. Email: Thomas.Steinmeier@TTU.edu
\end{abstract}

This research was supported by grant Number UM12-04 from the U.S. Social Security Administration (SSA) through the Michigan Retirement Research Center (MRRC) to the NBER. The findings and conclusions are solely those of the authors and do not represent the views of SSA, any agency of the Federal Government, MRRC, the NBER Retirement Research Center, or Boston College RRC. 


\begin{abstract}
This paper specifies three behavioral variants of a structural model of retirement and saving to bring predicted Social Security claiming rates closer to the rates observed in the data. The model, estimated with Health and Retirement Study data, is used to examine three potential policies: increasing early entitlement age, increasing normal retirement age, and eliminating payroll taxes after normal retirement age. Behavioral responses to increasing early entitlement age and eliminating the payroll tax are not affected by the behavioral variant used. Predicted effects of increasing the normal retirement age exhibit more sensitivity. Heterogeneity shapes the responses to these policy changes.
\end{abstract}




\section{Introduction}

Social Security continues to be under substantial financial pressure (Social Security Administration Trustees Report, 2012). A number of policy changes have been suggested to enhance solvency, bring liabilities more in line with revenue, and in the process, encourage a population that is becoming increasingly long lived to delay retirement. ${ }^{1}$ In this paper we examine the likely effects of three such policy changes, increasing Social Security's early entitlement age, raising the full (normal) retirement age, and eliminating the payroll tax for those over the full retirement age. We also consider the sensitivity of findings as to the effects of these policies to the features of the econometric model used to analyze their impact.

To understand the effects of these policy changes, one must have a model that is capable of jointly explaining retirement, saving and claiming behavior, and the distribution of these outcomes throughout the population. Accordingly, we specify and estimate an enhanced version of a dynamic, stochastic, structural model, where each of these outcomes is endogenously determined. Our estimates, based on a sample of married households from the Health and Retirement Study, generate the key behavioral parameters required to simulate the full effects of the proposed policy changes.

Policy analysts have had trouble in explaining claiming behavior. In particular, most models, including an earlier version of our model, do not explain why, given other aspects of their behavior, people claim their Social Security benefits as early as they do. The benefit adjustments offered by the Social Security system to those who delay claiming are sufficient for most analyses to suggest that claiming should be occurring at older ages than is found in the data.

Here we take two approaches to dealing with this problem. First, we modify the structure of the model to include stochastic returns to assets and reverse flows from states of greater to lesser retirement in our specification. Second, we introduce several behavioral modifications to the model that might explain early claiming and examine the

\footnotetext{
${ }^{1}$ For these and other policy suggestions, see Senate Committee on Aging (2010) and Congressional Budget Office, 2010.
} 
sensitivity of the model's predictions regarding potential changes in Social Security policies to these alternative specifications.

Our findings provide estimates of the increase in age of retirement in response to an increase in the early entitlement age, to an increase in the full retirement age, and to elimination of the employee's share of the payroll tax for those over the full retirement age. We find that, for the most part, the predicted responses of retirement to these policy changes are not very sensitive to whichever behavioral modification we use to explain early claiming. We do find that some of these policies generate substantial responses in retirement. More specifically, raising the early entitlement age to 64 will increase full time work at ages 62 and 63 by 11 to 13 percentage points. Increasing the full retirement age from 65 to 67 (for those in the original HRS cohort) would increase full-time work at age 64 by 1.5 to 2.5 percentage points. Eliminating the payroll tax for work after full retirement age would increase full-time work by 1.0 to 1.7 percentage points between the ages of 65 and 67.

The predicted effects of raising the early entitlement age and abolishing the employee's share of the payroll tax after full retirement age, the policy changes with greatest effect on retirement, are not affected significantly by adjustments introduced into the model to explain early claiming. The estimated effect on retirement of increasing the full retirement age is more sensitive to which explanation is taken to account for early claiming.

Section II provides some background information and discusses the relevant literature. Section III considers the actuarial valuation of the Social Security annuity and how it affects claiming behavior. A structural model of retirement, saving and claiming is developed in Section IV. It is estimated and its properties are examined through simulation in Section V. Section VI explores modifications of the model that would explain the excessive claiming at younger ages. The effects of the three key policies, increasing the early entitlement and full retirement ages, and abolishing the payroll tax for those over the full retirement age, are examined in Section VII, while Section VIII concludes. 


\section{Background}

The Social Security system affects a number of decisions made by older Americans towards the end of their working careers. These include choices as to how long and how much to work, how much to save to finance consumption after retirement, and when to begin receiving Social Security benefits. Each of these choices has characteristics that are well documented in the data.

Until the last couple of decades, the best known feature of the retirement hazard was the spike at full retirement age. In both national and international data, this spike was attributed to the failure of Social Security and pension plans to provide an actuarially fair adjustment to delayed retirement. In the U.S., changes in legislation increased the delayed retirement credit, abolished the earnings test after full retirement age, and raised incentives in pensions. These changes greatly reduced the spike in retirements around the full retirement age (Anderson, Gustman and Steinmeier, 1999; Gustman and Steinmeier, 2009).

The key feature of the retirement hazard became the spike at age 62, a feature that is almost certainly related to the Social Security early entitlement age. This spike has materialized in spite of the fact that delaying taking Social Security benefits beyond 62 is at least actuarially fair for most individuals and frequently much better than actuarially fair.

Savings, and the wealth generated by savings, are distributed quite heterogeneously in the population. Moreover, there is a wide variation in wealth holdings even among individuals at similar points in their life cycles and with similar earnings histories. Available evidence suggests there is considerable dispersion of wealth even among those with the same level of lifetime income (Gustman and Steinmeier, 1999; Venti and Wise, 2001). Evidence from the HRS also shows that there are a distressing number of age 50+ households with essentially no retirement savings. Among those with no savings outside of Social Security, many have had substantial earnings in the past. Models have no trouble generating a wide dispersion of wealth, but much of the time that dispersion arises because of the wide dispersion in income. Generating the dispersion of wealth for individuals with similar earnings histories is a difficult proposition. 
Regarding Social Security claiming, it has been difficult to explain why so many individuals seem to want to claim benefits as soon as possible even though it appears that it would be actuarially advantageous for them to wait. To be sure, many individuals delay claiming because they are still working and would not be able to collect benefits much if at all due to the earnings test. Among those who are not working, however, many appear to claim benefits as soon as they can, although a minority delays claiming even though they could receive benefits.

It has been even more challenging to construct models that capture the spike in claiming at age 62 while also accounting for the other related outcomes observable in the data. For the retirement spike at early entitlement age, models that rely on the incremental increase in the present value of benefits, the so-called deltas, fail because Social Security does not impose actuarial penalties at age 62 and the deltas are zero. Structural life-cycle models with low estimates of time preference have the same problem; they cannot account for the spike in retirements at the early entitlement age. But with high estimates of time preference, the model underestimates wealth.

A number of studies explore the effects of actuarial incentives on benefit claiming and/or retirement. Some studies simply document the budget constraint. These studies find that the reward structure is likely to encourage delayed claiming of Social Security benefits, especially in the year or two following eligibility for early entitlement. ${ }^{2}$ Other studies have analyzed the relation of retirement outcomes to the actuarial penalties in the law, and simulated the effects of Social Security reforms that increased actuarial fairness after the full retirement age. (See Lumsdaine and Mitchell, 1999, for a survey of early contributions.) Models of benefit claiming, however, have had the greatest difficulty in trying to explain the heavy early claiming of benefits despite actuarial incentives encouraging postponement of benefit receipt beyond the early entitlement age. The

\footnotetext{
${ }^{2}$ For example, it has been known for some time that at a 3 percent real interest rate, postponing benefit receipt results in increases in future benefits that are, for many individuals, better than actuarially fair (Gordon and Blinder, 1980; Feldstein and Samwick, 1992). Shoven and Slavov (2012a) explore the actuarial advantages to postponing benefit claiming in the current economic environment, characterized by low inflation and low interest rates.
} 
greatest underprediction is for those who retire before age 62 (Coile et al, 2002). ${ }^{3}$ Studies have also tried to relate changes in claiming outcomes to changes in policy. Typically these studies rely on difference-in-difference analysis, comparing outcomes between members of different cohorts. ${ }^{4}$

In the past several years we have developed a series of models whose main purpose is to jointly explain two of the three key outcomes: the age 62 retirement spike and the dispersion of wealth among households with similar earnings histories (e.g., see Gustman and Steinmeier, 2005.) These models estimate the extent of unobserved heterogeneity in time preference rates, which manifest themselves in the dispersion of wealth households have relative to their previous earnings history. Households with high time preference rates also tend to value future Social Security benefits less than actuarial calculations would suggest. For them, the earnings test starts to look more like a tax on earnings after the early entitlement age, and this may induce them to retire at that point. ${ }^{5}$

We previously used one of these models (Gustman and Steinmeier, 2004) to examine the issue of Social Security claiming. At that time, the model assumed a fixed, relatively low interest rate, and retirement was an irreversible decision. In that model, the predicted claiming behavior seemed to be less than the observed behavior, with the prediction error being greatest at ages prior to the normal retirement age. Since that time we have introduced stochastic returns to assets and the possibility of reentering the labor force into the model, but in the context of an assumption that individuals always claim benefits as soon as possible. It seems worthwhile now to reintroduce endogenous

\footnotetext{
${ }^{3}$ In Shoven and Slavov (2012b), claiming is a dependent variable, while retirement and wealth, jointly determined outcomes, are treated as explanatory variables.

${ }^{4}$ For example, Song and Manchester (2007) provide short-run estimates of the response of benefit claiming to the combined effects of increasing the full retirement age and abolishing the earnings test.

${ }^{5}$ A related literature explores the effects of the earnings test on retirement (e.g., Burtless and Moffitt, 1984; Disney and Smith, 2002; Friedberg, 2000; Gustman and Steinmeier, 1985 and 2004; and Song, 2002).
} 
claiming into the model and to determine whether these modifications improve the results regarding claiming behavior.

Stochastic returns to assets can cut two ways in this exercise. The mean rate of return is taken to be determined by a portfolio with half stocks and half bonds. This return is higher than the return on fixed assets we used in our previous work, which was taken as being equal to the rate used in the Social Security actuary's calculations. A higher return should raise the value of claiming early relative to waiting. On the other hand, the variance of the return makes the higher mean return somewhat less attractive, working in the other direction. This last effect would be somewhat mitigated by the possibility of returning to work, since the income loss from bad draws from the distribution of returns on assets could be offset to some degree by returning to work.

In sum, our goal is to isolate the effects of Social Security incentives on claiming behavior, especially at and around the early entitlement age. We hope to make progress in the context of a model in which retirement and saving are treated as jointly determined outcomes.

\section{Annuities.}

The central feature in the claiming decision is the tradeoff between a present lump sum and a future annuity. In this light, it will be helpful to spend a few paragraphs looking at how individuals value annuities such as Social Security. ${ }^{6}$

The value of an annuity to an individual can be broken down into two parts. First, there is the question as to the actuarial fairness of the annuity. That is, how does the present financial value of the stream of annuity payments, discounted at an appropriate interest rate, compare to the cost of the annuity? Second, there is the question as to how the individual values the stream of annuity payments relative to its present financial value. In other words, how much would the individual be willing to pay currently to receive the annuity, and how does this compare to the cost of an actuarially fair annuity? For purposes of analyzing claiming behavior, we are interested in the characteristics of a

\footnotetext{
${ }^{6}$ For discussions of the demand for the Social Security annuity, see Brown, Casey and Mitchell (2007).
} 
marginal annuity. Social Security and possible defined benefit pensions already provide a base level annuity, and the result of a delay in claiming adds a marginal amount to this annuity.

The actuarial value of the Social Security annuity has been extensively documented, so the discussion here will be brief. The general conclusion is that while the benefits of delaying claiming are roughly actuarially neutral for single individuals, at least until they reach their mid-60's, there is a strong actuarial advantage for the higher earner of a two earner couple to delay claiming benefits. When the individuals are 62 , they are eligible for 80 percent of their full benefits, assuming a normal retirement age of 65 (which is appropriate for much of the HRS sample). If they wait until age 63, they are eligible for 86.7 percent of their full benefits, which is an 8.3 percent increase. This increase will apply over their own lifetimes, and a substantial part will also apply over the lifetime of their surviving spouses.

Table 1 gives the actuarial rates for delaying claiming for several circumstances. ${ }^{7}$ The first column pertains to the higher earner of a couple, where the spouse is two years younger, with a real interest rate of 2 percent. The first entry indicates that at age 62, for every dollar of benefits lost because the individual delays claiming, the present value of the increased later benefits will be $\$ 1.67$. That is, by claiming at age 62 , the individual gives up future benefits that would have an actuarial value that is 67 percent higher. This actuarial advantage declines as the individual delays further, but even at age 69 the tradeoff of present benefits for future benefits is approximately actuarially fair. As shown in the second column, the advantage declines for a real interest rate of 4 percent, but is still more than actuarially fair for ages prior to the full retirement age. The last column looks at a single individual, and it would also apply to the perceived actuarial calculations for a married individual who gave no weight to the utility of a surviving spouse. These figures indicate that the future increases are roughly actuarially fair until the normal retirement age and decline sharply during the late 60's.

\footnotetext{
${ }^{7}$ For a recent related analysis of the actuarial advantage to delayed claiming and references to the previous literature, see Shoven and Slavov (2012b).
} 
The other part of the annuity question is how much individuals would be willing to pay for an actuarially fair annuity. This can be investigated with the aid of a very simple consumption model. Let total utility be given by

$$
\mathrm{U}=\sum_{\mathrm{t}} \mathrm{s}_{\mathrm{t}}\left(\frac{1}{1+\rho}\right)^{\mathrm{t}} \mathrm{u}\left(\mathrm{c}_{\mathrm{t}}\right)
$$

Where $s_{t}$ is the survival rate until time $t$ and $\rho$ is the discount rate. Non-annuitized assets start at some level $\mathrm{a}_{0}$ and evolve according to the standard formula

$$
a_{t+1}=(1+r) a_{t}+b-c_{t}, \quad a_{t+1} \geq 0
$$

where $r$ is the real interest rate and $b$ is the level of annuities from Social Security and possibly defined benefit pensions. As long as non-annuitized assets are positive, the first order conditions yield

$$
\mathrm{u}_{\mathrm{c}}\left(\mathrm{c}_{\mathrm{t}}\right)=\frac{1}{\mathrm{~s}_{\mathrm{t}}}\left(\frac{1+\rho}{1+\mathrm{r}}\right)^{\mathrm{t}} \mathrm{u}_{\mathrm{c}}\left(\mathrm{c}_{0}\right)
$$

Eventually at advanced ages, $s_{t}$ starts to fall rapidly, causing $u_{c}\left(c_{t}\right)$ to rise and consumption to fall.

The fall in consumption while non-annuitized assets are positive indicates a twopart solution. In the first part, consumption starts at some level $\mathrm{c}_{0}$ and evolves according to the first order condition as long as non-annuitized assets are positive. At some point the level of consumption implied by the first order condition falls below the level of the annuity $b$. At that point, assets reach zero and consumption then follows b. Two extreme cases are that the individual starts out with almost no assets or that the individual starts out with so many assets that they never reach zero. In the first case, the value of an additional $\$ 1$ of annuity is $\sum \frac{\mathrm{s}_{\mathrm{t}}}{(1+\rho)^{\mathrm{t}}}$ the cost of an actuarially fair annuity is $\sum \frac{s_{t}}{(1+r)^{t}}$, and the ratio of value to cost is $\sum \frac{s_{t}}{(1+\rho)^{t}} / \sum \frac{s_{t}}{(1+r)^{t}}$. In the second case, the value is $\sum \frac{1}{(1+r)^{t}}$, the cost is the same, and the ratio of value to cost is 


$$
\sum \frac{1}{(1+r)^{t}} / \sum \frac{s_{t}}{(1+r)^{t}} \text {. In the intermediate case, where assets are depleted at time } B \text {, }
$$

the ratio of the value to cost is given by

$$
\left(\sum_{t=0}^{B-1} \frac{1}{(1+r)^{t}}+\frac{1}{(1+r)^{B}} \sum_{t=B}^{D} \frac{s_{t}}{s_{B}} \frac{1}{(1+\rho)^{t-B}}\right) / \sum_{t=0}^{D} \frac{s_{t}}{(1+r)^{t}}
$$

where $\mathrm{D}$ is the maximum age of survival. This reduces to the first expression when $\mathrm{B}=$ 0 and to the second expression when $\mathrm{B}=\mathrm{D}$.

Tabulations of the ratio of annuity value to cost for several scenarios are given in Table 2. For instance, the value of 1.38 in the first row indicates that an individual currently aged 62 whose assets will run out at age 80 along the optimal consumption path would be willing to pay 38 percent more than the cost of an actually fair annuity if the real interest rate were 2 percent and the individual's discount rate was 0 . There are several things to note about this table. If the individual's discount rate is relatively low, he or she is likely to have accumulated substantial assets by retirement, and because of the low discount rate these assets are likely to last very late into the life cycle. Therefore, for individuals with a low discount rate, the columns on the right side of the table are most likely to be relevant. These columns suggest that annuities are likely to be of considerable value to these individuals. Not only do these individuals give relatively more weight to later years, but the actuarially fair cost of providing the annuity in those years is relatively low. Recall also that this value is on top of any actuarial advantage of Social Security delay, so for low discount married individuals with earnings higher than their spouses, the value of the increased future benefits may well be double the value of the current benefits foregone by delaying claiming.

Individuals with high discount rates, on the other hand, are unlikely to have amassed much in the way of assets by the time of retirement, and their high preference for current consumption means that whatever assets they do have will not last for long. This means that for individuals with high discount rates, the columns on the left of the 
table are more likely to be relevant. As indicated in the third group of figures in the table, an individual with few assets and a relatively high discount rate (0.04) may find that the value of the marginal annuity is actually less than the actuarially fair cost of that annuity. In the limit, an individual with a very high discount rate and almost no assets may find that the value of the marginal annuity arising from delaying claiming would be almost zero, in which case anything that causes a delay in claiming (such as the earnings test) would act effectively like a tax.

This creates something of a dilemma for policymakers. Ideally, one would like individuals with high discount rates to choose to delay claiming benefits to obtain an increased annuity income, since they do not have very many assets to fall back on and are probably least prepared financially for retirement. However, those individuals are precisely the ones who place the least value on the annuity and hence are the least likely to choose to delay claiming benefits. Individuals with low discount rates, who are probably much better prepared financially for retirement, are the ones most likely to value the annuity provided by delaying claiming.

The last three rows of the table indicate that increasing the interest rate has different effects on different groups of people. Compare these rows with the second group of three rows, which have the same discount rate but a lower interest rate. For individuals with a lot of assets whose assets will last until a relatively old age, an increased interest rate will make the marginal annuity less attractive. The reason appears to be that the increased interest rate downplays the later years, when the annuity is most valuable relative to its cost. On the other hand, for individuals with few assets who will deplete those assets relatively quickly, the higher interest rate makes the annuity more valuable relative to its cost. This appears to be because the higher interest rate reduces the cost of the annuity, whereas the value of the annuity for these individuals is governed more by the discount rate, which has not changed. The interest rate thus has an ambiguous effect on the value of an annuity relative to its cost, even among individuals with the same discount rate.

In summary, the relationship between the amount that individuals would be willing to pay for the annuity provided by delaying claiming and the amount given up by 
foregoing current benefits varies over a wide range. The higher earning individual in a couple with substantial assets and a low discount rate will find delaying extremely advantageous, while a single individual over the normal retirement age with few assets and a high discount rate may find it extremely disadvantageous to delay claiming. The commonly expressed feeling that individuals with relatively few assets should appreciate the opportunity to insure themselves against living too long is erroneous, especially if the cause of the low level of assets is that the individuals have relatively high discount rates. The opposite view, that individuals with low asset levels are likely to regard themselves as over-annuitized and are willing to trade at least some of their future annuity for an actuarially equivalent present lump sum, is oftentimes more nearly correct.

\section{The Structural Model.}

We now turn to the complete structural model that will be estimated and simulated in this paper. The core of the model is an expected utility function

$$
\mathrm{EU}=\mathrm{u}\left(\mathrm{C}_{0}, \mathrm{~L}_{0}\right)+\sum_{\mathrm{t}=1}^{\mathrm{D}}\left[\left(\frac{1}{1+\rho}\right)^{\mathrm{t}} \sum_{\mathrm{m}=1}^{3} \mathrm{~s}_{\mathrm{m}, \mathrm{t}} \mathrm{u}\left(\mathrm{C}_{\mathrm{t}}, \mathrm{L}_{\mathrm{t}}\right)\right]
$$

Where $\mathrm{C}$ is consumption, $\mathrm{L}$ is leisure, $\mathrm{m}$ is an index that indicates the survival state of the household, and $\mathrm{s}_{\mathrm{m}, \mathrm{t}}$ is the probability that the household survives to time $\mathrm{t}$ in state $\mathrm{m}$. The three states are that both spouses have survived, only the husband has survived, and only the wife has survived. Due to computational limitations arising from the addition of claiming variables into the model, the wife's labor supply is taken as exogenous, so that the leisure variable in the utility function is the husband's leisure.

The within period utility function is given by

$$
\mathrm{u}\left(\mathrm{C}_{\mathrm{t}}, \mathrm{L}_{\mathrm{t}}\right)=\frac{1}{\alpha} \mathrm{C}_{\mathrm{t}}^{\alpha}+\mathrm{e}^{\beta_{0}+\beta_{\mathrm{a}} \mathrm{Age}_{\mathrm{t}}+\beta_{\mathrm{h}} \text { Health }_{\mathrm{t}}+\varepsilon_{\mathrm{t}}} \mathrm{L}^{\gamma}
$$

The coefficient in front of the leisure term indicates the relative weight of leisure in the utility function. In this formulation, leisure gradually gets more valuable relative to work due to physical and mental exhaustion, and a bout of bad health adds to this relative preference for leisure. The $\varepsilon$ term is an individual effect that varies from individual to individual and reflects that individual's relative preference for leisure. 
Consumption and leisure are chosen to maximize expected utility subject to the budget constraint

$$
A_{t+1}=\left(1+r_{t}\right) A_{t}+E\left(L_{t}\right)+S_{t}+P_{t}+O_{t}-C_{t}, \quad A_{t+1} \geq 0
$$

where $\mathrm{E}$ is earnings, $\mathrm{S}$ is Social Security benefits, $\mathrm{P}$ is pension benefits, and $\mathrm{O}$ is other income. The return on assets $\mathrm{r}$ is taken to be stochastic and uncorrelated over time. Earnings depend on the amount of leisure, and the wage rate may vary depending on the amount of work the individual chooses. Social Security and pension benefits are the actual amounts paid in a year, and not a measure of accruals. As such, for instance, $\mathrm{S}$ is zero before the Social Security early entitlement age, and $\mathrm{P}$ is zero before the individual has retired from the job generating the pension.

The model is estimated for a sample of married households in the original cohort of the Health and Retirement Study (HRS). The original HRS included individuals aged 51 to 61 in 1992 and surveyed those individuals every two years starting in 1992. In addition to a large number of economic and labor force variables, the HRS has two supplements that are useful for this study. The first is the earnings records from the Social Security Administration, and the second is the pension plan descriptions from the providers of the pensions held by the respondents. These two allow for much more precise measurement of the economic incentives faced by the households. The two main requirements for a household to be included in our sample are that the husband must have been full-time in the labor force most years before age 50 with at least some indication of his wage either from the Social Security earnings records or self reports, and if he had a defined benefit pension in his current job at the time the survey starts, or the last job held before the start of the survey, the pension must be included in the pension provider survey. The latter exclusion arises because if an individual had a pension, but the details of the pension are not available from the provider survey, it is very unlikely that the incentives that the individual faced to retire at particular ages will be correctly reflected in the budget constraint.

In the model, leisure is restricted to three values: 0 for full time work, $1 / 2$ for partial retirement work, and 1 for full retirement. In the earnings function $\mathrm{E}$, the wages may differ according to the amount of work. For full-time work before retirement, wages 
for years not directly observed are imputed using coefficients for experience and tenure from a fixed effects wage regression. Unobserved partial retirement wages are inferred from a regression of observed partial retirement wages on full-time wages and other variables. Wages for full-time jobs which individuals have taken after a period of either full or partial retirement are inferred by resetting the tenure variable to zero.

The Social Security benefit amount, which is central to the issues investigated in this paper, is taken to be determined by three state variables in the model. The first of these is the level of the primary insurance amount (PIA) of the husband, which is determined by the age at which the husband leaves full-time work initially. The presumption is that partial retirement jobs, which tend to have lower wages than full-time work, will not significantly impact the PIA. The other two state variables are the adjustment amounts for both the husband and wife, reflecting both any early retirement penalties and delayed retirement credits. If the individual has the maximum adjustment amount relative to his or her age, this indicates that the individual has not claimed any previous benefits, and that individual may delay claiming further if that is the optimal strategy. Once benefits are claimed, the adjustment amount may be recalculated if the individual is subject to the earnings test and loses benefits in a particular year. The PIA of the wife enters implicitly as an exogenous variable, since it is determined by the exogenous work history of the wife.

The pension benefit variable takes on a different form depending on whether the pension is defined benefit or defined contribution. In both cases, the pension benefit variable is zero before the individual retires from the pension job. In a defined benefit pension, the amount of the benefit is fixed at the time the individual leaves the job by applying the applicable formula from the pension provider documents to the earnings history and tenure that the individual had compiled in that job. For defined contribution pensions, a state variable is created to reflect the balance in the defined contribution account. Year by year, contributions are made to the plan, and the accumulated balance is augmented by the same rate of return that is applied to the non-pension assets. The entire balance is presumed to be made available to the individual in the year following the last 
year in the job. At that time, the balance of the defined contribution plan is effectively added to the non-pension assets.

The other income variable is primarily composed in most cases of the earnings of the wife. It also includes any pension amounts due to the wife, calculated on the same basis as the pension benefits due to the husband. A final inclusion in some cases is any inheritances that the household receives.

The model contains three important elements of preference heterogeneity. The most important of these is the discount rate reflecting time preference. This is treated as a fixed effect whose value for every household is calculated as the value for which the asset amount calculated by the model matches the observed level of assets in the initial year of the survey. As suggested by the results of the previous section, variations in the discount rate may play an important role in the differing responses of households to opportunities to gain additional annuity amounts by delaying the claiming of Social Security benefits. The second element of heterogeneity is the initial value of the leisure preference parameter $\varepsilon$. This value is presumed to be taken from a distribution with mean 0 and standard deviation $\sigma_{\varepsilon}$.

The third element of heterogeneity relates to the relative desire for partial retirement. Recall that leisure has the three values $0,1 / 2$, and 1 . For these values of $\mathrm{L}$, $\mathrm{L}^{\gamma}$ has the three values $0,(1 / 2)^{\gamma}$, and 1 . Thus, $\gamma$ effectively determines the utility of partial retirement. For the marginal utility of leisure to be declining, $\gamma$ must be between 0 and 1 , and $(1 / 2)^{\gamma}$ must be between $1 / 2$ and 1 . If $(1 / 2)^{\gamma}$ is closer to $1 / 2$, the value of leisure will be proportional to the amount of leisure, and individuals will tend to choose either full retirement or full-time work depending on whether the value of leisure exceeds the wage or not. If $(1 / 2)^{\gamma}$ is closer to 1 , then partial retirement leisure is almost as valuable as the leisure in full retirement, and the individual is more likely to go through a period of partial retirement. This model supposes that $x=(1 / 2)^{\gamma}$ is drawn from an exponential distribution $f(x)=g(\delta) e^{\delta x}$ truncated below $1 / 2$ and above 1 , where $g(\delta)$ is a term of proportionality to make $f(x)$ integrate to 1 between $1 / 2$ and 1 . The value of $\delta$ changes over time according to $\delta=\delta_{0}+\delta_{1}$ Age to reflect that partial retirement may become more desirable over time as the individual grows older. As the value of $\delta$ 
changes over time, however, we assume that the individual's relative position within the distribution stays the same.

The principal stochastic element in the model is the rate of return on assets, which comes from a normal distribution with a mean and standard deviation reflecting the observed behavior of a portfolio of roughly half stocks and half short-term government bonds over an extended period of time. A second stochastic element is that after the individual initially retires, the value of $\varepsilon$ may unexpectedly change, reflecting that retirement may be more or less enjoyable than anticipated. This is accomplished by introducing a correlation parameter $\rho_{\varepsilon}$ which measures the correlation of $\varepsilon$ in adjacent periods after the individual retires.

There are eight parameters in the complete model: $\alpha$ (the exponent of consumption), $\beta_{0}, \beta_{\mathrm{a}}$, and $\beta_{\mathrm{h}}$ (which affect the weight of leisure in the utility function), $\sigma_{\varepsilon}$ and $\rho_{\varepsilon}$ (which influence the variance of leisure preferences and how they change over time), and $\delta_{0}$ and $\delta_{1}$ (which determine the distribution of partial retirement preferences). State variables in the model, which mediate how past decisions and stochastic events affect the present decisions and how present decisions will affect future circumstances, include the following: the level of assets; whether or not the individual is still in the career job; the level of defined contribution balances if the individual has a defined contribution pension; the primary insurance amount; the Social Security adjustment amounts for both the husband and wife; the pension benefit if the individual had a defined pension; and the value of leisure relative to consumption.

Given values for the parameters, a value of the discount rate $\rho$ is calculated using the observed or expected retirement dates and estimating a consumption model for the resulting income. Previous research has shown that this gives a good approximation to the median value of $\rho$. This approach has the advantage that it guarantees that the distribution of assets from the model approximately matches the observed distribution, conditional on lifetime wages and other measures of economic opportunities. Given this value of $\rho$, the model is solved by backwards induction in the usual process for dynamic stochastic models. 
Estimation is achieved using the method of simulated moments technique. This technique chooses the parameter values to best match the moments generated by the model to the corresponding moments observed in the data. Since there are many more moments than there are parameters, the model will be unable to fit all of the moments perfectly, but if the model is correctly specified there should not be any instances where the moments generated by the model are wildly different from the observed moments. The moments that are used are the retirement percentages for both full and partial retirement by age and by health status and lifetime income level, and the percentages of time that individuals return to work after an initial period of full or partial retirement. Moments relating to claiming behavior of the individuals in the sample are not used in the estimation, for two reasons. First, one of the objectives of this project is to see how close one can come to generating realistic claiming behavior as a result of optimizing a model built around a retirement decision. And secondly, there are really no parameters in the model that can substantially influence claiming behavior in any case.

\section{Estimates and Base Simulations.}

The model is estimated for the HRS sample previously described, with the results for the parameters being given in Table 3. With the exception of $\delta_{1}$, all of the coefficients are individually significantly different from zero at any reasonable level of significance. For a method of moments estimation, if the model is correctly specified, the q statistic is randomly distributed according to a $\chi^{2}$ distribution with degrees of freedom equal to the number of moments used minus the number of parameters estimated. The current estimates use 43 moments and the model has 8 parameters, so the $\chi^{2}$ distribution has 35 degrees of freedom. A $\chi^{2}$ distribution with 35 degrees of freedom has a 5 percent significance value of 49.8 and a 10 percent significance value of 46.1 , as compared to the 43.9 value calculated for the estimates. Since low values of $\chi^{2}$ are consistent with the model being correct, this result does not reject the hypothesis that the model is correct.

By themselves, though, the parameters of the model are somewhat difficult to interpret. Therefore, we turn to a comparison of the results of simulations with the model 
to observed distributions. These simulations use 10,000 replications per observation, so there should not be much sampling variance in the simulated results.

The first set of simulations tracks the proportion of married men in work and retirement. Figure 1 depicts the difference between the percentage of full-time workers at one age and the corresponding percentage one year later. This might be called the pseudo-retirement percentage, because it is the net result of individuals newly retired from full-time work and a smaller group who were previously retired but returned to fulltime work. The most notable feature of this figure is the large spike at age 62. Over 15 percent of the married men in the sample retired at this age, and this spike is fairly well captured in the simulations. It should be emphasized that there is nothing in the utility function that would produce this result; it is the response to the incentives in the budget constraint. It does not occur simply because some individuals have no savings, since they could always switch to a partial retirement job and have at least some income. Rather, it occurs because individuals with fairly high discount rates and relatively low savings often find that the earnings test serves to reduce their effective compensation at age 62. A second considerably lower spike occurs in the data at age 65 , but in the simulations this spike is not much more than a bump. It is likely that this spike arises in the data because of Medicare eligibility, which is not included in the model.

Figure 2 shows the corresponding transitions into full retirement. The spike at age 62 is not quite so large here, either in the data or in the simulation. A plausible explanation for this is that because of the earnings disregard for the earnings test, the earnings test does not bite into partial retirement earnings quite so much as it does fulltime earnings. In this figure, also note that the age 65 spike is muted as well. This probably occurs because fewer partial retirement jobs have health insurance than do fulltime jobs, so that eligibility for Medicare is not quite so important.

Figure 3 indicates the percentage of husbands claiming Social Security benefits by age, relative to the observed percentages. The simulated percentages are substantially below the observed amounts, especially at the ages before the full retirement age. It had been hoped that the stochastic additions to this model, including stochastic returns to assets and the possibility that some of the previous retired individuals return to work, 
would have increased the percentage of individuals claiming benefits in the simulations, but evidently this is not the case. These results do reflect the common feeling of many who have examined this issue: that claiming is higher than would be expected, given the actuarial benefits of delaying claiming. (E.g., most recently, see Henriques, 2012.) The percentage of wives who claim benefits is substantially higher, starting at 60 percent at age 62 and rising to 90 percent by age 66 .

\section{Modifications to the Model.}

There are several potential explanations as to why claiming in the model falls below the levels of claiming observed. In this section, we will look at three of them, introduce them into the model, and assess the degree to which these explanations can explain the relatively high levels of claiming.

The first explanation to be examined is that individuals do not give full weight to future Social Security benefits because they question the solvency of the system and have some doubts whether they will actually receive the full benefits to which the present rules entitle them. Figure 4 gives the results of a simulation in which individuals assumed that future Social Security benefits would be a fraction of the currently legislated benefits. The original simulated results and observed results are repeated from the previous figure, and the green line in the graph represents the new simulation. In this simulation, the $\beta_{0}$ parameter is adjusted so that the levels of retirement remain at approximately the same level as before. The simulation strongly suggests that the discrepancy between the original simulated results and the observed results can be accounted for if it is presumed that individuals do not believe that they will receive their legislated benefits. The main problem is with the magnitude of the change required to achieve this effect: the simulation supposes that individuals believe that beginning at age 70 , they will receive only 50 percent of their legislated benefits. This number would strike many people as low, particularly for the HRS cohort whose retirement occurred largely in the 1990's.

There is a second problem with this explanation. Over time, it would seem that doubts about the future benefits would have increased as the projected time when the trust fund will be exhausted has crept into the possible lifetimes of individuals currently 
making claiming decisions. If a greater likelihood of reductions in future benefits would cause individuals to be more likely to claim earlier so as to receive benefits before the reductions occur, the claiming rate should be increasing over time. But this is not what has been happening in recent years.

A second explanation of the underestimate of claiming by the current model is that individuals are more optimistic about asset returns than the model assumes. The mean return used in the model is the historical mean of the Ibbotson series dating back to the 1926, but individuals may be using a different period with a higher mean. The simulation in Figure 5 uses a higher mean return than is used in the base simulation. The result of this simulation almost overlays the observed data. The main difficulty with this simulation is again with the magnitude: the mean rate of return is increased by 5 percentage points over the historical series, a rate that many might regard as a bit high.

This explanation, however, does have the advantage that it is more or less consistent with recent trends. The 1990's, during which much of the retirement of the original HRS cohort occurred, was a period of heady returns. During that time, there was a lot of discussion about the poor returns of Social Security, and individuals were likely to claim as soon as possible in order to take advantage of those returns. In the last dozen years, however, the picture has been much different. Real returns have been inching down into negative territory, and the discussion about the poor returns to Social Security has largely ceased. The recent downturn in claiming would certainly be consistent with generally lower expectations regarding the returns to assets.

The third explanation for why the model may underestimate claiming behavior has to do with the assumption in the model that the husband provides equal weight to his and his wife's utility, weighted only by the discount rate and survival probabilities. The experience with pensions in past decades certainly gives some reason to suspect this assumption. Before there were any regulations, many if not most husbands with defined benefit pensions took those pensions as single life annuities, even given a roughly actuarially fair opportunity to convert them to annuities that would pay the wife in the case he died first. The fact that so many widows were left destitute by this practice led to regulations that made it substantially more difficult for a married person to take a defined 
benefit pension as a single life annuity. The same behavior may lead the husband to discount the benefits to the wife after his death when making the claiming decision.

Figure 6 shows the results of a simulation wherein the husband does not give any weight to the wife's survivor benefits after he dies. Somewhat surprisingly, the lack of concern for the wife's survivor benefits does not make a great deal of difference in the claiming behavior in the simulation, especially in the early years of eligibility for Social Security. To understand this result, recall that the majority of survivor benefits will come only after many years have passed. Any calculation that gives much weight to these years will of necessity have a fairly low discount rate. But at low discount rates, the value of the marginal Social Security annuity relative to its cost is probably fairly high, even if the wife's survivor benefits are ignored. After the normal retirement age, this advantage starts to erode, and the simulations predict claiming behavior closer to the observed claiming behavior if the individual does not take into account the wife's survivor benefits.

While all three of these explanations have some weak points, they are not mutually exclusive. It may be that two of three of them in combination would provide an adequate explanation of the observed claiming behavior without invoking implausible assumptions. In the present paper, we are not able to distinguish very well among these explanations, but in the next section it is possible to ask whether these explanations create any differences in the results of potential policy changes in which we might be interested.

\section{Policy Analysis.}

In this section we explore the effects of three commonly proposed changes to the Social Security system in order to increase employment and increase the solvency of the system. They are an increase in the early entitlement age, an increase in the normal retirement age, and an elimination of the payroll tax after an individual has reached the normal retirement age. In each case, we will look at simulations for the base case and also at simulations that reflect the three potential explanations for the underestimation of claiming examined in the previous section. 
Figure 7 looks at the results for the simulations involving increasing the early entitlement age to 64. The base case and all three modifications of the model are in remarkable agreement in this case: full-time employment will be little affected before age 62 or after age 64, and at ages 62 and 63 full-time employment will increase by approximately 12 percentage points. Essentially, the spike in retirement from full-time work which presently occurs at age 62 would be shifted to age 64 by this change. The solvency of the system will be increased by the extra two years of payroll taxes for the group that delays, but this must be balanced against the fact that for most of these individuals, delaying benefits will result in more than actuarially fair adjustments to later benefits, which will cost the system in the long run.

Figure 8 examines the results for the simulations involving increasing the normal retirement age to 67 , whereas it was age 65 for most of the individuals in the sample. In the figure, "insolvency" refers to the simulation where individuals expect reduced future benefits due to solvency concerns about the system, "returns" refers to the simulation with the increased returns on assets, and "survivor" refers to the simulation wherein the husband discounts the benefits that would be paid to his surviving spouse were he to die first. These simulations show somewhat greater variability than the simulations in Figure 7, but in general they show two things: the increases in full-time work caused by increasing the normal retirement age are substantially less than the increases caused by raising the early entitlement age, and the impact of raising the normal retirement age is generally positive. The outlier appears to be the simulation which reduces expectations that individuals will receive their full legislated benefits; the results of the other three simulations are relatively much closer. In terms of relieving the Social Security shortfall, however, this is probably a much more effective change than is raising only the early entitlement age. Whereas an increase in the early entitlement age mostly postpones benefits, an increase in the normal retirement age without an offsetting change in the full benefit serves effectively to reduce considerably the present value of lifetime benefits.

Figure 9 shows the results of simulations for eliminating the payroll tax after the normal retirement age. This simulation shows the result of eliminating only that part of the tax paid by the employee; if the employer's side of the tax were eliminated and if that 
saving were to be passed on to employees, one would expect the resulting magnitudes to be roughly double the amounts shown. The simulations also assume that for ages for which the payroll taxes are eliminated, earnings for those ages are not used in the PIA calculations. These simulations indicate a relative agreement between the base simulation and those simulations incorporating the various explanations for the claiming underestimates in the base model. They all show a reduction in full-time work of between 0.5 and 1 percent between age 60 and age 64 and an increase in full-time work of between 1 and 2 percent at age 65 and thereafter. Summed over all the ages, the net result seems to be an increase in full-time effort, with some shifting of work effort from the period when compensation in unchanged to the period when effective compensation has increased.

\section{Conclusion.}

This paper has examined the effects of three potential policy changes: changes in the early entitlement age, in the normal retirement age, and the elimination of the payroll tax for workers over the normal retirement age. In the analysis, three behavioral variants of the model are used in an attempt to bring the predicted claiming rates closer to the observed claiming rates. For two of the policy changes, namely an increase in the early entitlement age and the elimination of the payroll tax, the model gives consistent answers regardless of which behavioral variant is used. There is more dispersion in predicted effects for an increase in the normal retirement age, but even here most of the dispersion is due to one of the behavioral variants, namely the variant using a severe reduction in expected future benefits. Of the three potential policy changes, an increase in the early entitlement age clearly has the most impact on retirement, although the increase in the normal retirement age probably has the most impact on the solvency of the system.

Our estimates reinforce the notion that it is difficult to explain claiming behavior with a straightforward life-cycle model, even one with stochastic asset returns and the possibility of returning to work after retirement. However, three plausible variants do permit the model to better match simulated claiming behavior with observed behavior without much affecting other positive advantages of the model, including the ability to 
replicate the spike in retirement at the early entitlement age. The variant that best appears to remedy the problem of underestimating claiming and still be consistent with the reduction in claiming over the last few years is one in which individuals use shorter horizons in forming their expectations about returns to assets. Since expectations regarding asset returns have fallen considerably recently, claiming relatively early is becoming less attractive against the alternative of waiting to claim benefits and having future Social Security payments be larger.

A recurring theme of our research is that in designing policies, it is helpful to be cognizant of the heterogeneous population and that policies may have different impacts on different parts of the population. For instance, current Social Security rules allow individuals to trade current benefits for better than actuarially fair increases in future benefits. Ideally, this would allow individuals with low levels of assets to secure an increased level of steady income for the rest of their lives. But individuals with low levels of assets frequently are in that situation because of a relatively high discount rate, and such individuals are unlikely to take advantage of the offer to trade present benefits for increased future benefits. Thus, policymakers face a situation in which individuals who would benefit most from delaying claiming are the least likely to respond to incentives to delay claiming.

In the same vein, an increase in the early entitlement age may have the greatest effect on those with high discount rates. Individuals with high discount rates may not think that the future benefit increases are worth giving up current benefits, and with few assets they may be forced to work more than they would otherwise find optimal. Of course, that is the way they feel during the period when the benefits are being delayed; ten years later, they may feel glad that they are receiving higher benefits than they would have received had they been able to claim those benefits earlier. The situation is much different for those with low discount rates. Such individuals will most likely have a relatively higher level of assets relative to earnings. They may well find that it is advantageous to delay claiming anyway, since for them the future benefit increases outweigh the current benefits foregone, and they can live off their assets in the meantime even if they are retired. 
Another example would be future medical expenditures. Financial planners have recently been increasingly sounding the alarm about potential high out-of-pocket expenditures for medical expenses in retirement. Individuals with low discount rates may respond to high and variable potential expenditures for medical expenses by increasing saving, working longer, and other measures. Those with higher discount rates may not respond much at all to the prospect of higher medical expenses in what is for them the distant future. If they do wind up with substantial medical expenses, they will simply be forced to tighten their belts and rely on whatever programs exist to keep them out of poverty.

The paper raises a number of questions for future research. It investigated several explanations of why individuals might want to begin claiming Social Security benefits even though actuarial and even utility calculations might suggest that it would be advantageous to delay, and it is has noted at least some recent evidence that might favor one of these explanations. But it would certainly be helpful to have more evidence on this score. Also, the model emphasizes heterogeneity in time preference as an important aspect of modeling individuals' behavior, and to a lesser degree heterogeneity in leisure preferences. In the limit, with preferences differing in unobservable ways, it is important to try to ascertain what unobserved dimensions of heterogeneity are critical to answering the questions at hand, and to try to build those dimensions of unobserved heterogeneity into the appropriate model. 


\section{References}

Anderson, Patricia M., Alan L. Gustman, and Thomas L. Steinmeier. 1999.

"Trends in Male Labor Force Participation and Retirement: Some Evidence on the Role of Pensions and Social Security in the 1970s and 1980s." Journal of Labor Economics, 17(4): 757-783.

Brown, Jeffrey R., Marcus D. Casey and Olivia S. Mitchell. 2007. "Who Values the Social Security Annuity: New Evidence on the Annuitization Puzzle". Unpublished manuscript.

Burtless, Gary and Robert Moffitt. 1984. "The Joint Choice of Retirement Age and Postretirement Hours of Work.” Journal of Labor Economics 3(2): 209-236.

Coile, Courtney, Peter Diamond, Jonathan Gruber and Alain Jousten. 2002. "Delays in claiming Social Security benefits". Journal of Public Economics 84: 357-385

Congressional Budget Office. 2010. "Social Security Policy Options”.

Disney, Richard and Sarah Smith. 2002. "The Labor Supply Effects of the Abolition of the Earnings Rule for Older Workers in the United States". The Economic Journal 112: C136-C152.

Feldstein, Martin and Andrew Samwick. 1992. "Social Security Rules and Marginal Tax Rates". National Tax Journal 45: 1-22.

Friedberg, Leora. 2000. "The Labor Supply Effects of the Social Security Earnings Test." The Review of Economics and Statistics 82 (1): 48-63.

Gordon, Roger H. and Alan S. Blinder. 1980. "Market Wages, Reservation Wages and Retirement". Journal of Public Economics 14: 277-308.

Gustman, Alan L. and Thomas L. Steinmeier. 1985. "The 1983 Social Security Reforms and Labor Supply Adjustments of Older Individuals in the Long Run". Journal of Labor Economics 3(2): 237-253. 1999. "Effects of Pensions on Savings: Analysis with Data From the Health and Retirement Study". Carnegie-Rochester Conference Series, vol. 50 (July, 1999) pp. 271-326. 
.2004. "The Social Security Retirement Earnings Test,

Retirement and Benefit Claiming.” Working Paper 10905. Cambridge, Mass.: National Bureau of Economic Research. .2005. "The Social Security Early Retirement Age In A

Structural Model of Retirement and Wealth," with Thomas Steinmeier. Journal of Public Economics. Volume 89, Issues 2-3 (February 2005): 441-463. .2009. "How Changes in Social Security Affect Recent

Retirement Trends," with Thomas Steinmeier. Research on Aging. March, 2009. Vol. 31, No. 2: 261-290.

Henriques, Alice M. 2012. "How Does Social Security Claiming Respond to Incentives? Considering Husbands' and Wives' Benefits Separately". Washington, D.C. Federal Reserve Board.

Shoven, John B and Sita Nataraj Slavov. 2012a."The Decision to Delay Social Security Benefits: Theory and Evidence". NBER Working Paper No. 17866. .2012b. "When Does it Pay to Delay Social Security?

The Impact of Mortality, Interest Rates, and Program Rules". NBER Working Paper No. 18210.

Senate Committee on Aging. 2010. "Social Security Modernization: Options to Address Solvency and Benefit Adequacy". Report of the Special Committee on Aging, United States Senate.

Song, Jae G. 2002. "Evaluating the Effects of the Removal of the Retirement Earnings Test in 2000”. Mimeo. Social Security Administration. November.

Song, Jae and Joyce Manchester. 2007. "Have People Delayed Claiming Retirement Benefits?" Social Security Bulletin 67(2): 1-23.

Social Security Administration Trustees Report. 2012. "The 2012 Annual Report of the Board of Trustees of the Federal Old-Age and Survivors Insurance and Federal Disability Insurance Trust Funds". Washington, D.C. 
Venti, Steven F. and David A. Wise. 2001. "Choice, Chance, and Wealth Dispersion at Retirement". In S. Ogura, T. Tachibanaki, and D. Wise (ed.) Aging Issues in the United States and Japan. University of Chicago Press. 
Table 1

Actuarial Rates for Claiming at Various Ages

$\begin{array}{cccc}\begin{array}{c}\text { Real Interest Rate } \\ \text { Marital Status } \\ \text { Claiming Age }\end{array} & \begin{array}{c}0.02 \\ \text { Married }\end{array} & \begin{array}{c}0.04 \\ \text { Married }\end{array} & \begin{array}{c}0.02 \\ \text { Single }\end{array} \\ 62 & 1.67 & 1.31 & 1.18 \\ 63 & 1.50 & 1.18 & 1.05 \\ 64 & 1.36 & 1.08 & 0.95 \\ 65 & 1.48 & 1.18 & 1.02 \\ 66 & 1.33 & 1.07 & 0.91 \\ 67 & 1.20 & 0.97 & 0.82 \\ 68 & 1.09 & 0.89 & 0.74 \\ 69 & 0.99 & 0.81 & 0.66\end{array}$

Table 2

Annuities: Willingness to Pay vs. Actuarial Value

\begin{tabular}{|c|c|c|c|c|c|c|c|}
\hline \multirow{2}{*}{$\begin{array}{c}\text { Real } \\
\text { Interest } \\
\text { Rate }\end{array}$} & \multirow{2}{*}{$\begin{array}{c}\text { Discount } \\
\text { Rate }\end{array}$} & \multirow{2}{*}{$\begin{array}{c}\text { Current } \\
\text { Age }\end{array}$} & \multicolumn{5}{|c|}{ Age When Assets Become Zero } \\
\hline & & & Immediate & 70 & 80 & 90 & 100 \\
\hline \multirow{3}{*}{0.02} & \multirow{3}{*}{0.00} & 62 & 1.23 & 1.25 & 1.38 & 1.60 & 1.78 \\
\hline & & 65 & 1.21 & 1.23 & 1.39 & 1.65 & 1.85 \\
\hline & & 70 & 1.17 & 1.17 & 1.37 & 1.72 & 1.99 \\
\hline \multirow{3}{*}{0.02} & \multirow{3}{*}{0.02} & 62 & 1.00 & 1.14 & 1.34 & 1.59 & 1.78 \\
\hline & & 65 & 1.00 & 1.11 & 1.35 & 1.64 & 1.85 \\
\hline & & 70 & 1.00 & 1.00 & 1.32 & 1.70 & 1.99 \\
\hline \multirow{3}{*}{0.02} & \multirow{3}{*}{0.04} & 62 & 0.83 & 1.05 & 1.32 & 1.58 & 1.78 \\
\hline & & 65 & 0.85 & 1.01 & 1.31 & 1.63 & 1.85 \\
\hline & & 70 & 0.87 & 0.87 & 1.28 & 1.69 & 1.99 \\
\hline \multirow{3}{*}{0.04} & \multirow{3}{*}{0.02} & 62 & 1.20 & 1.21 & 1.32 & 1.48 & 1.59 \\
\hline & & 65 & 1.18 & 1.21 & 1.34 & 1.53 & 1.66 \\
\hline & & 70 & 1.15 & 1.15 & 1.34 & 1.61 & 1.80 \\
\hline
\end{tabular}


Table 3

Parameter Estimates

\begin{tabular}{|c|c|c|}
\hline Parameter & Description & $\begin{array}{c}\text { Value } \\
\text { (Standard Deviation) }\end{array}$ \\
\hline$\alpha$ & Exponent of consumption & $\begin{array}{l}-0.16 \\
(3.36)\end{array}$ \\
\hline$\beta_{0}$ & $\begin{array}{l}\text { Constant in leisure value } \\
\text { expression }\end{array}$ & $\begin{array}{r}-9.558 \\
(408.81)\end{array}$ \\
\hline$\beta_{\mathrm{a}}$ & $\begin{array}{l}\text { Coefficient of age in leisure } \\
\text { value expression }\end{array}$ & $\begin{array}{r}0.067 \\
(6.54)\end{array}$ \\
\hline$\beta_{\mathrm{h}}$ & $\begin{array}{l}\text { Coefficient of health in } \\
\text { leisure value expression }\end{array}$ & $\begin{array}{l}5.70 \\
(7.40)\end{array}$ \\
\hline$\sigma_{\varepsilon}$ & $\begin{array}{l}\text { Standard deviation of } \varepsilon \text { in } \\
\text { leisure value expression }\end{array}$ & $\begin{array}{c}5.87 \\
(9.33)\end{array}$ \\
\hline$\rho_{\varepsilon}$ & $\begin{array}{l}\text { Correlation of } \varepsilon \text { after } \\
\text { retirement }\end{array}$ & $\begin{array}{c}0.71 \\
(5.72)\end{array}$ \\
\hline$\delta_{0}$ & $\begin{array}{l}\text { Constant term in partial } \\
\text { retirement distribution }\end{array}$ & $\begin{array}{l}-3.62 \\
(8.00)\end{array}$ \\
\hline$\delta_{1}$ & $\begin{array}{l}\text { Coefficient of age in partial } \\
\text { retirement distribution }\end{array}$ & $\begin{array}{l}0.16 \\
(1.60)\end{array}$ \\
\hline $\begin{array}{l}\text { Numbe } \\
\text { q-statis }\end{array}$ & $\begin{array}{l}\text { r of observations: } \\
\text { tic: }\end{array}$ & $\begin{array}{r}2231 \\
43.94\end{array}$ \\
\hline
\end{tabular}


Figure 1

Retirements from Full-Time Work

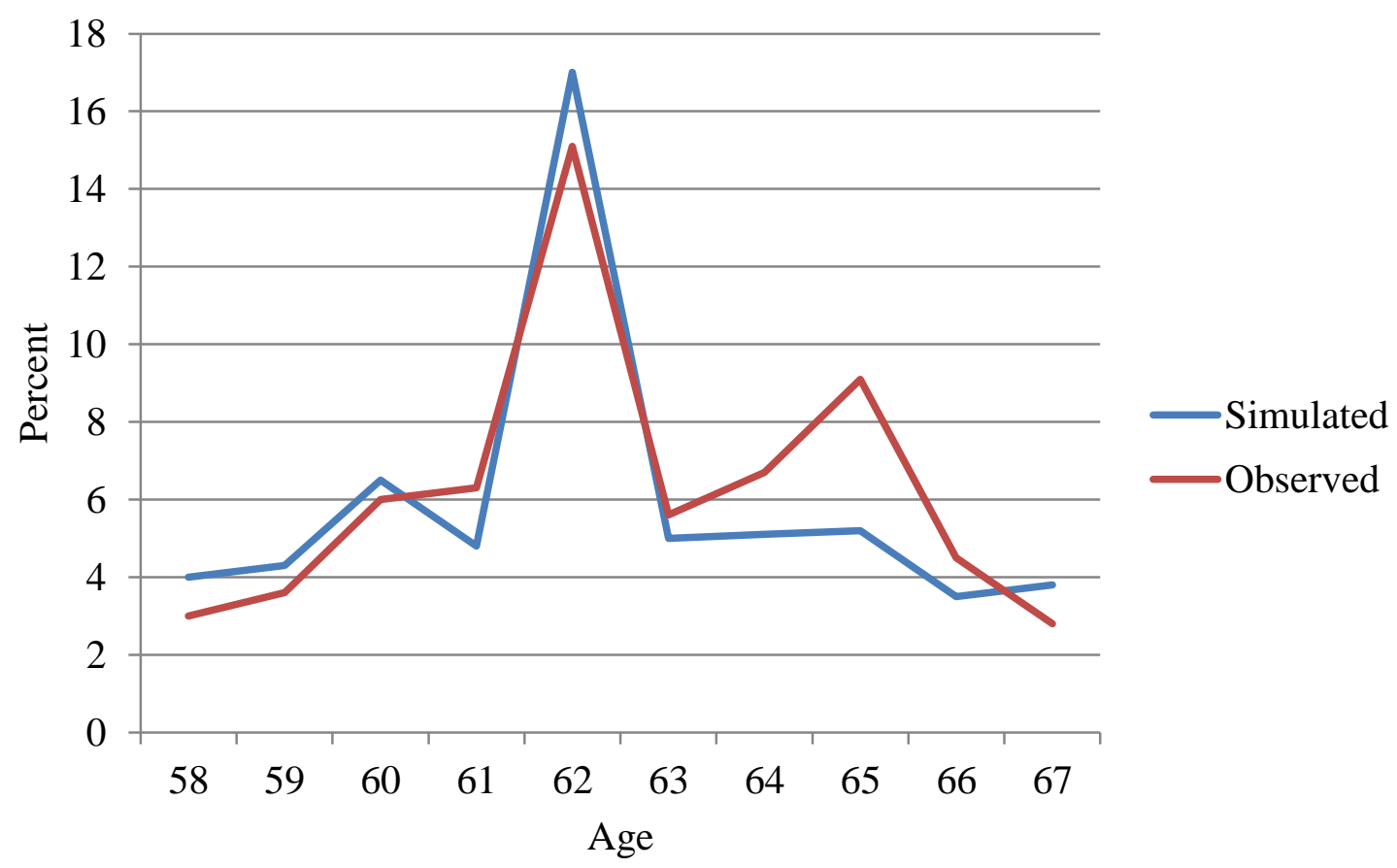

Figure 2

Retirements from All Work

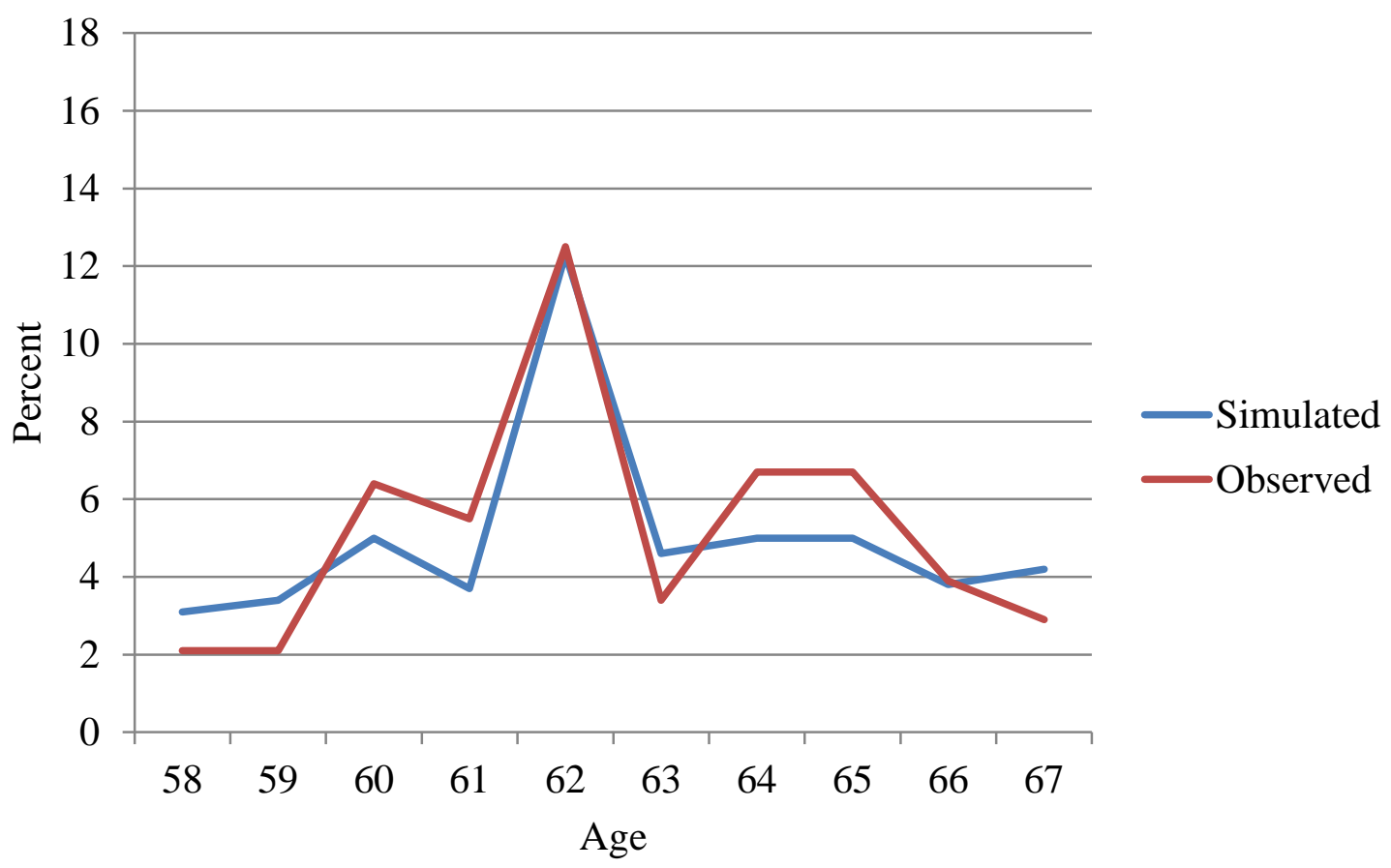


Figure 3

Percent Claiming Social Security Benefits

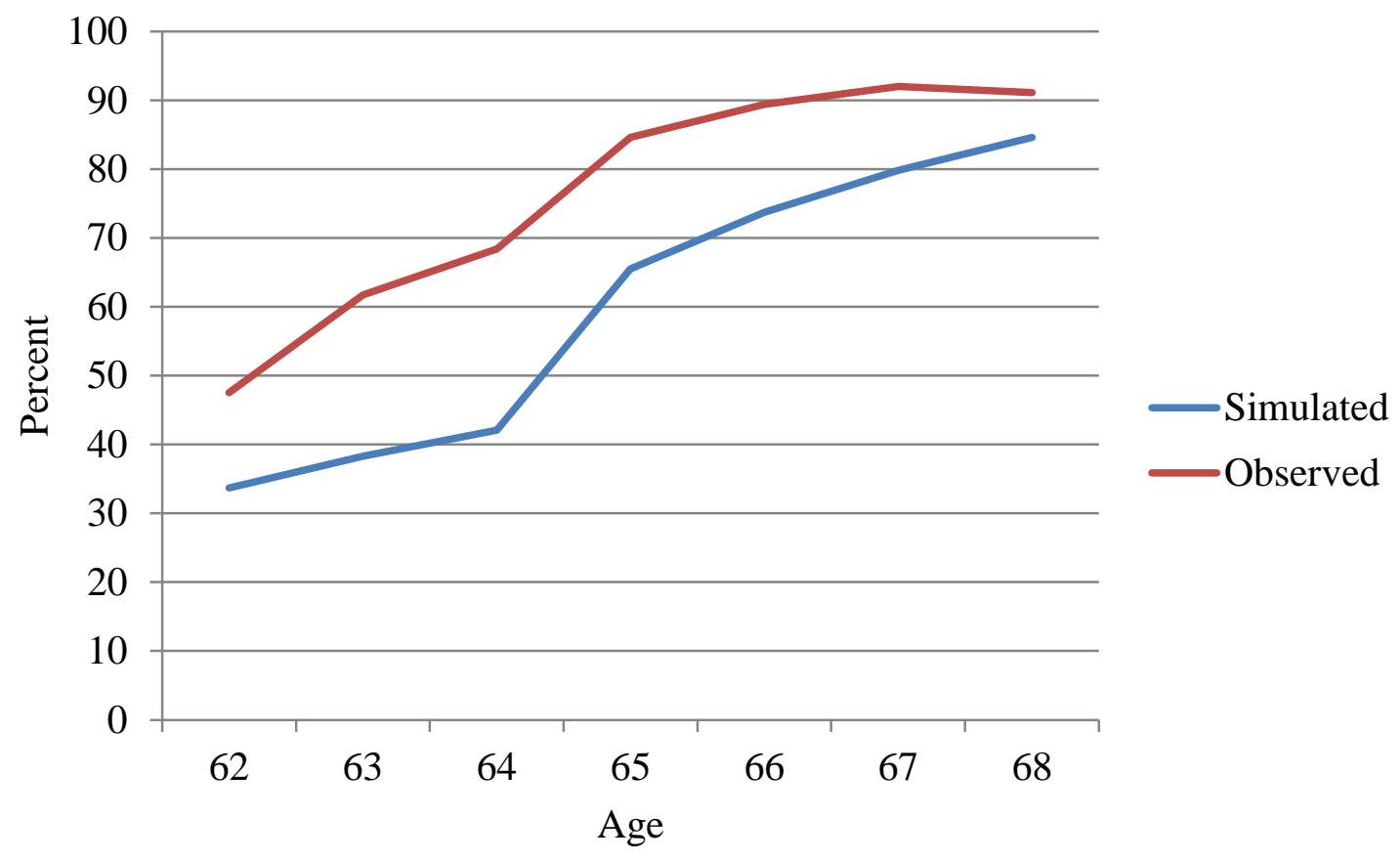

Figure 4

Simulation with Reduced Expectations of Receipt

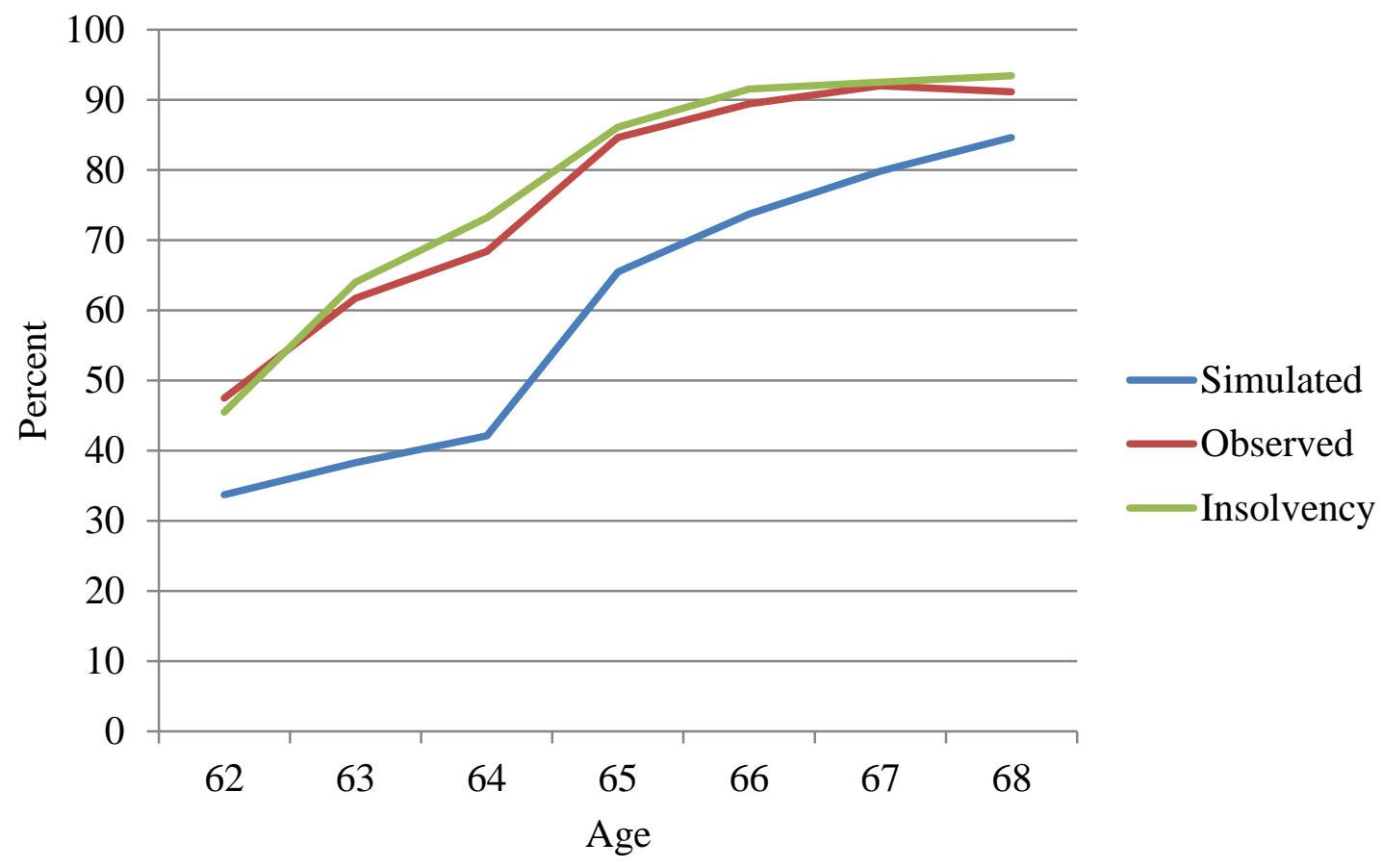


Figure 5

Simulation with Increased Return on Assets

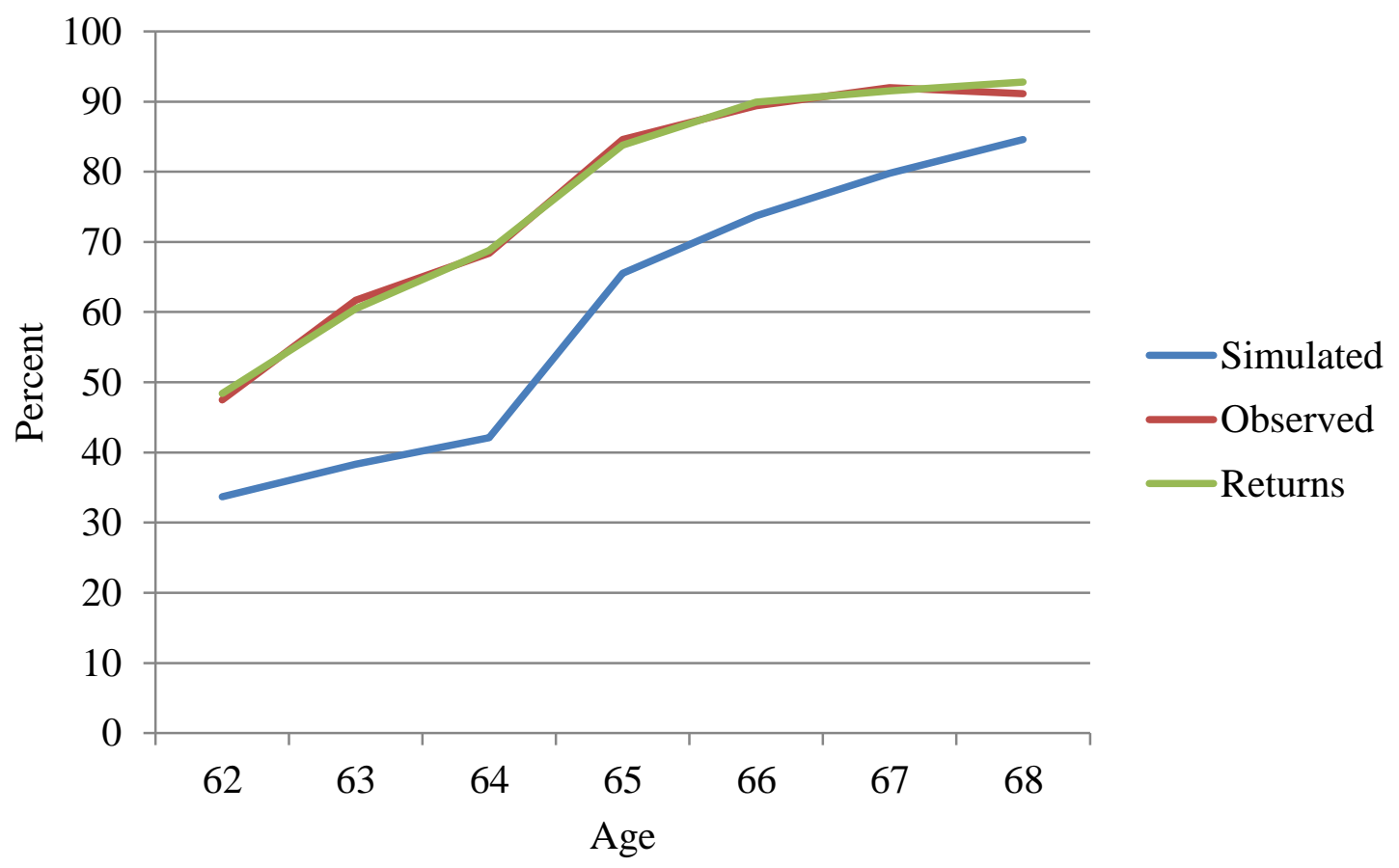

Figure 6

Simulation with Survivor Benefits Ignored by Husband

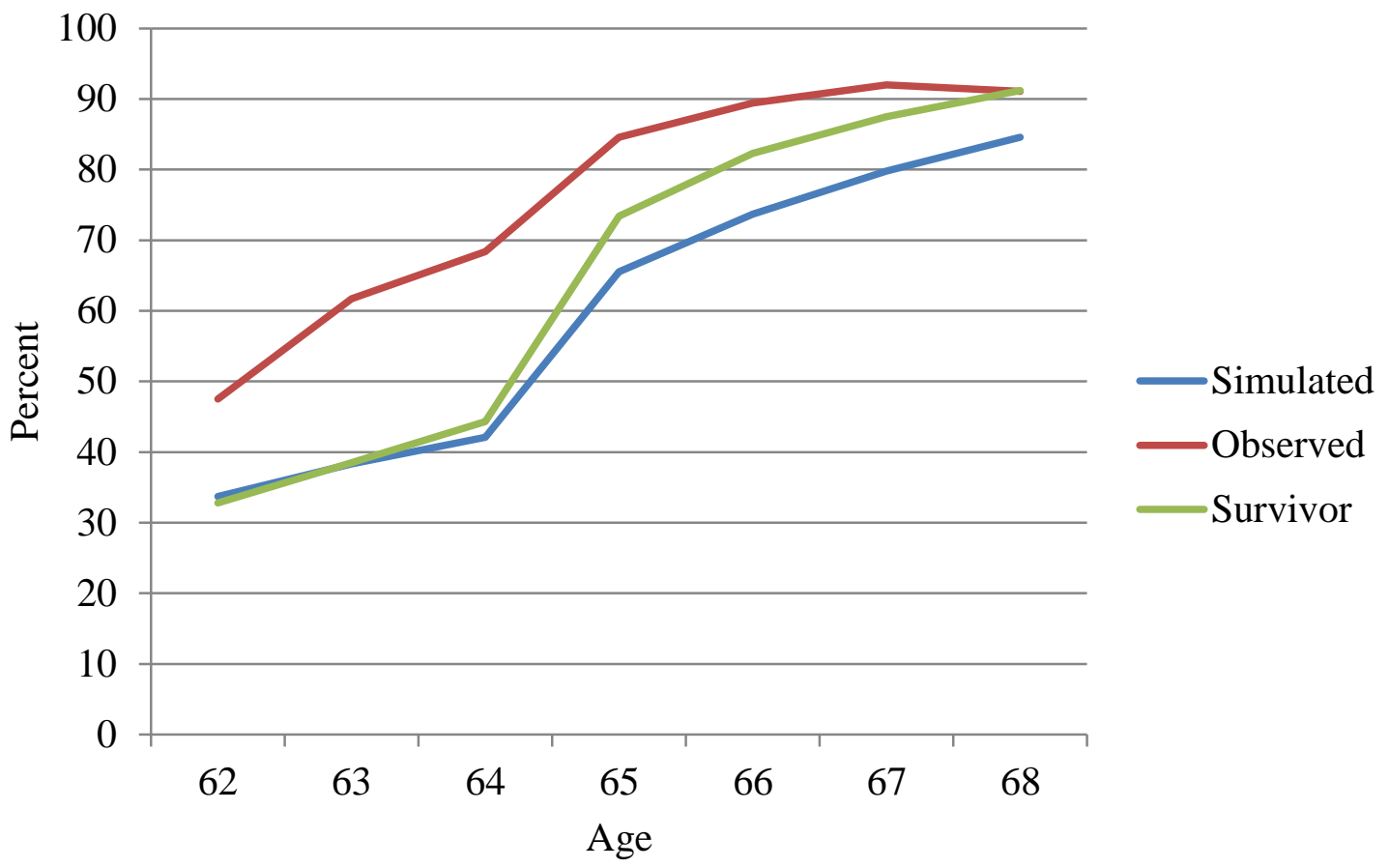


Figure 7

Increase in Full-Time Work with Early Entitlement Age 64

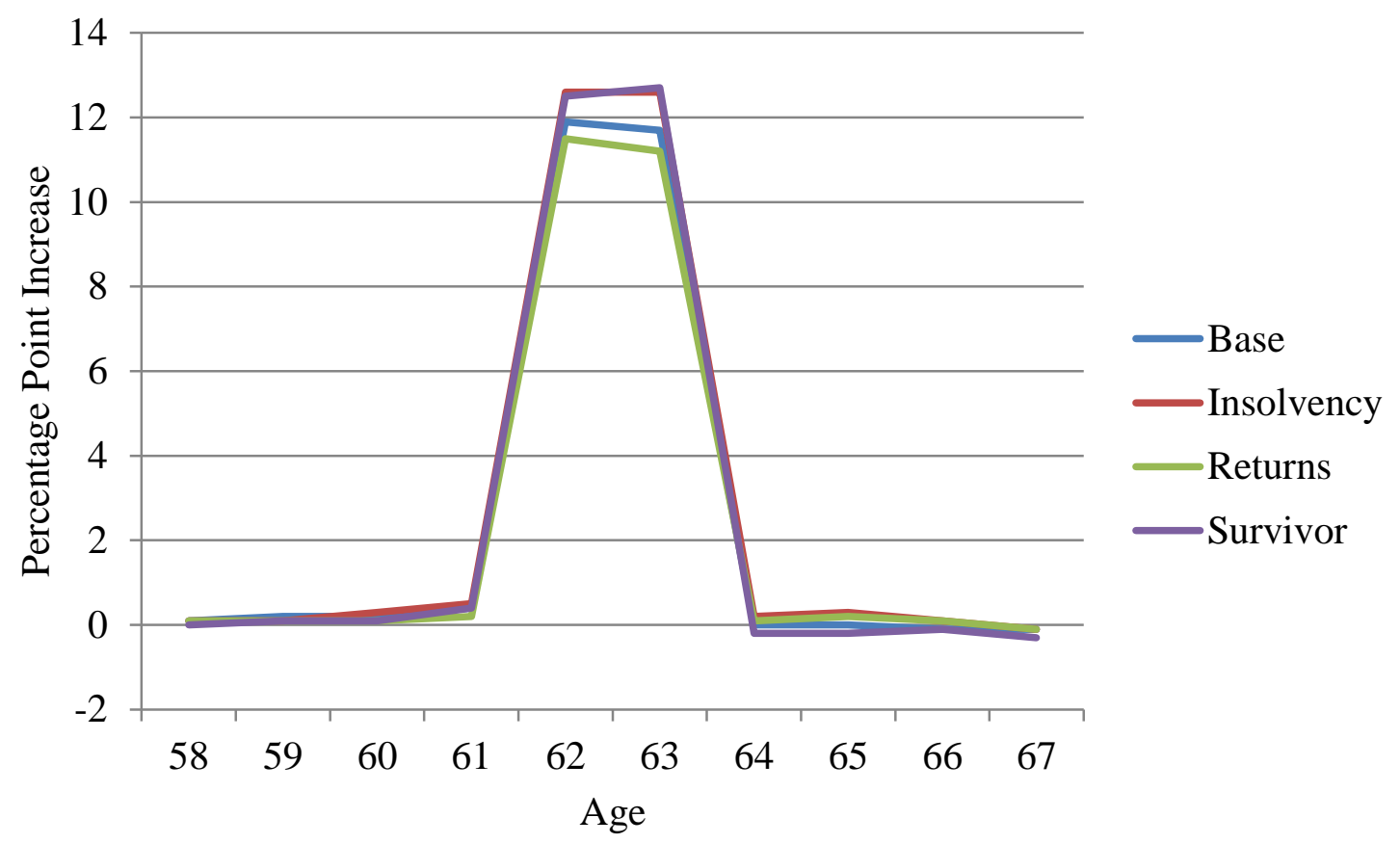

Figure 8

Increase in Full-Time Work with Normal Retirement Age 67

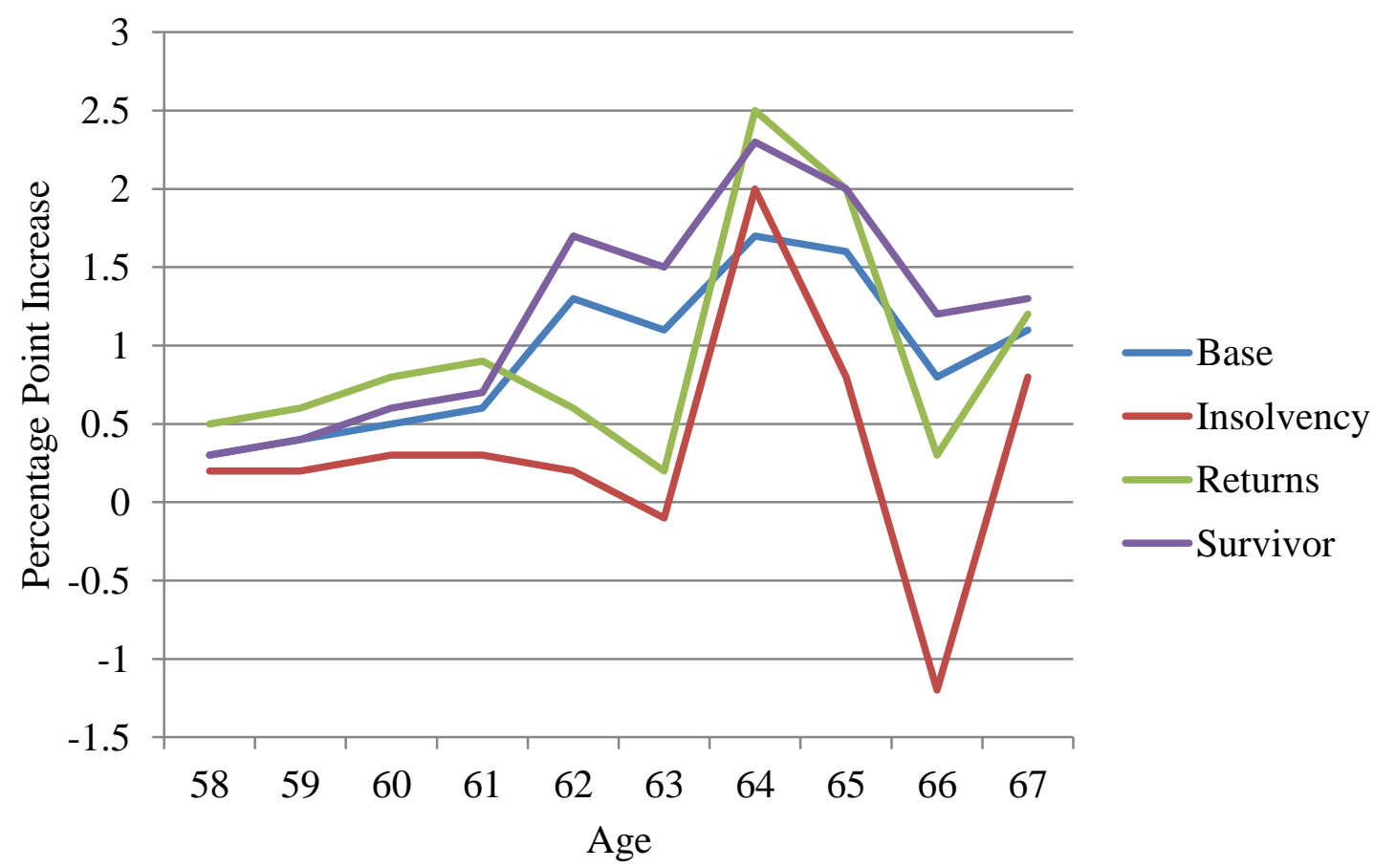


Figure 9

Increase in Full-Time Work with No Payroll Tax After Normal

Retirement Age

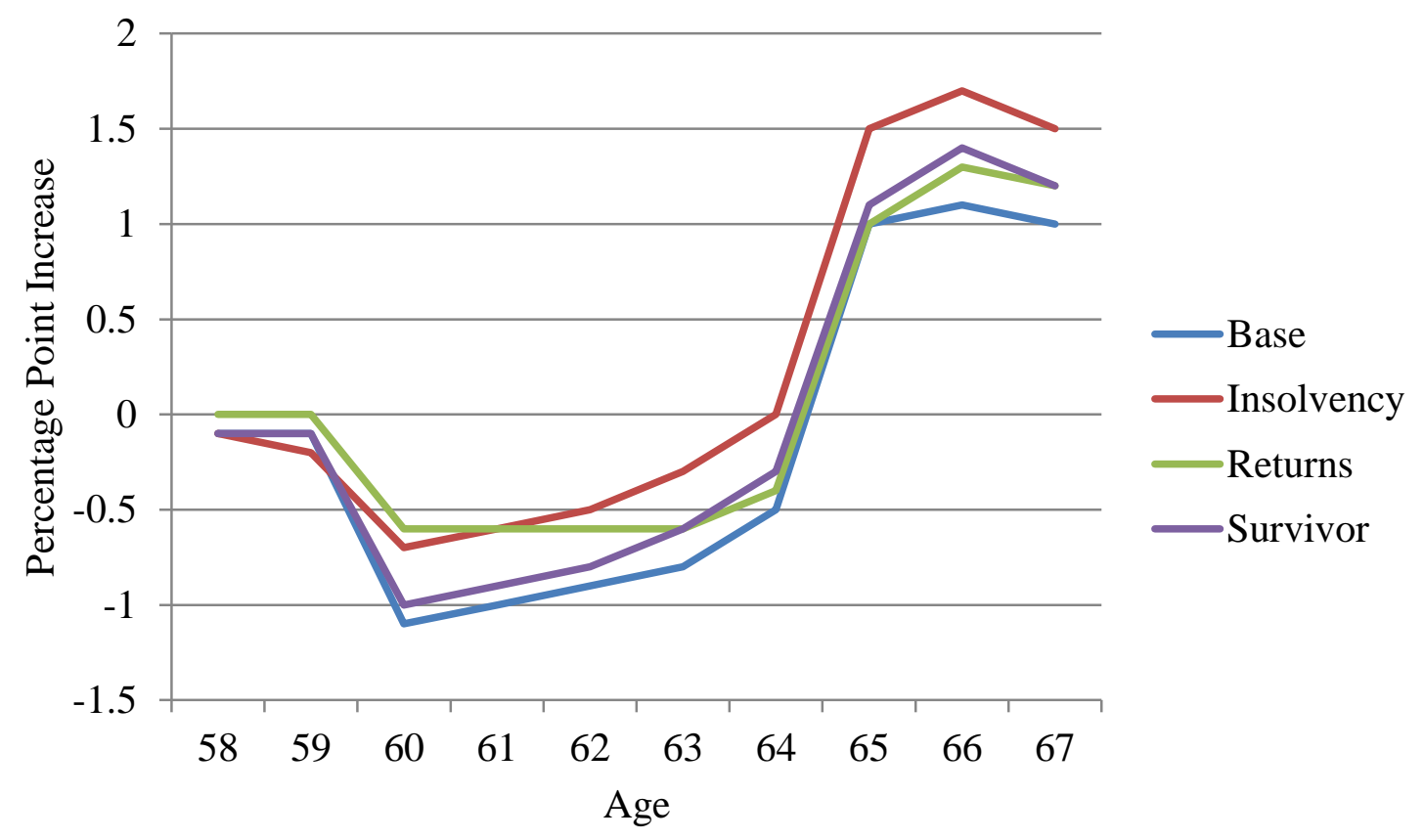

